\title{
Judith Butler y la formación melancólica del sujeto
}

\author{
Patricia Romano \\ Universidad Autónoma de \\ Chapingo
}

Con este trabajo se busca recuperar los componentes centrales de la teoría de Judith Butler respecto a la formación del sujeto que aparece en The Psychic Life of Power. ${ }^{1}$ En esta teoría la autora considera y destaca la importancia de la dimensión psíquica del poder social en la formación del sujeto. La propuesta más sobresaliente, sin duda, es la introducción y el análisis de esa dimensión por medio de la noción de identificación melancólica, y su argumentación en cuanto a que ésta es el fundamento en la delimitación de los espacios interno y externo. Esta propuesta puede ser considerada como un acercamiento teórico para entender el funcionamiento del poder social en la construcción de la identidad.

Nuestro texto se organiza en cuatro secciones: Primero se expone la trayectoria de la autora y se ubica su obra; en segundo lugar se explican los argumentos más destacados en la teoría de la formación del sujeto, poniendo énfasis en el carácter de la incorporación melancólica; después se detalla su relectura de Foucault y Althusser con relación a los efectos psíquicos del poder y los efectos formativos de la prohibición, por considerarlos un apoyo para su argumentación sobre la incorporación melancólica; por último, se considera el alcance que esta autora atribuye a la identificación melancólica en la formación del género.

${ }^{1}$ Judith Butler, The Psychic Life of Power: Theories in Subjection, Stanford, Calif., Stanford University Press, 1977.

Economía, Sociedad y Territorio, vol. II, núm. 5, 1999, 313-327. 
Judith Butler fue profesora de humanidades en la Universidad Johns Hopkins. Actualmente es profesora de Literatura comparada y retórica en la Universidad de California en Berkeley. La obra de Butler puede circunscribirse al campo de las teorías sociopsicológicas que abordan las diferencias de género desde una perspectiva fenomenológica. En este ámbito, ella se ha convertido en una de las autoras más importantes; sus trabajos teóricos sobre poder, género, sexualidad e identidad, han sido ampliamente difundidos y hoy día se encuentra encabezando las propuestas teóricas sobre homosexualidad (queer theory). Uno de los esfuerzos más importantes de esta autora radica en su intento por establecer los puentes entre la teoría del poder, fundamentalmente en términos de Foucault, y la teoría psicoanalítica. El libro más difundido de Butler es sin duda Gender Trouble, ${ }^{2}$ en el que plantea por primera vez sus ideas en torno a la representatividad del género. Siguiendo esta línea, más tarde publica Bodies that Matter, ${ }^{3}$ y finalmente, el libro que ahora se analiza. Butler cuenta por lo menos con otras cuatro publicaciones importantes, pero desde mi punto de vista las referidas establecen un continuo en sus concepciones acerca del poder, el género y la identidad.

The Psychic Life of Power, al igual que sus otros trabajos, es un libro con un nivel de argumentación teórica elevado, tiene que ser leído detenidamente, una y otra vez, para aclarar conceptos. No obstante, es también un libro que anima a la reflexión con propuestas que no necesariamente se circunscriben a la identidad de género, sino que permite incorporar en la lectura la constitución de la identidad en sentido amplio. En este libro Butler combina teoría social, filosofía y psicoanálisis, y su trabajo puede ser considerado como una reflexión filosófica o como un trabajo netamente teórico; sin embargo, ella lleva sus ideas a situaciones concretas tales como la prostitución, la homosexualidad, el travestismo, entre otras, para esclarecer sus puntos de vista.

Con la intención de efectuar un análisis crítico de la sujeción, Butler desarrolla la teoría sobre la formación del sujeto, que incluye el dominio psíquico y una explicación de los mecanismos con los cuales el sujeto es formado en sumisión. Ella pretende demostrar la manera en que el poder social produce formas de reflexividad, al mismo tiempo que limita las formas de

\footnotetext{
${ }^{2}$ Judith Butler, Gender Trouble: Feminism and the Subversion of Identity, Nueva York, Routledge, 1990.

${ }^{3}$ Judith Butler, Bodies that Matter: On the Discursive limits of "Sex", Nueva York, Routledge, 1993.
} 
sociabilidad. En esta tarea la autora establece los puentes conceptuales entre Hegel, Nietzsche, Freud, Foucault y Althusser, en lo que se refiere a la producción y regulación del sujeto. La autora identifica un paralelo entre la "inevitabilidad" 4 del cuerpo en el pensamiento de Hegel, la del instinto en Freud, y de la voluntad en Nietzsche, y sugiere que los tres clásicos circunscriben un tipo de inversión dialéctica que se centra en la imposibilidad de una supresión reflexiva total o final de lo que podría llamarse "el cuerpo". Además sostiene que Hegel asume tácitamente la sujeción como un apego de autonegación, que en términos operativos es similar a la noción freudiana de inversión libidinal. Es decir, en Hegel los imperativos éticos autoimpuestos buscan instituir la negación o el sacrificio de la vida corporal, pero el cuerpo es al mismo tiempo conservado por esos imperativos, ya que no puede haber una negación total-equivaldría a la muerte-; el miedo a la muerte sería el origen de tales imperativos; por medio del sacrificio corporal el sujeto se apega a su propio cuerpo. De la misma manera, en el pensamiento de Freud la libido no es completamente negada por medio de la represión, sino que aquélla es conservada gracias a ésta. También, asegura que la preocupación de Foucault sobre las implicaciones de la sujeción (la formación simultánea y la regulación del sujeto) aparece, de alguna manera, en la dialéctica del amo y el esclavo en Hegel, en particular, respecto a la explicación de Hegel sobre la liberación del esclavo en diferentes formas de autocondena ética, que buscan instituir la negación o el sacrificio corporales. ${ }^{5}$

Un aspecto sobresaliente en este trabajo es que el poder no se concibe como "internalizado" por un sujeto, sino que el sujeto es generado como un efecto ambivalente del poder, que se hace presente por medio de la operación de la conciencia. En este sentido, Butler desafía las propuestas de que el sujeto aparece como "domesticado" por adelantado, fatalmente ligado a las condiciones del poder social que le son impuestas, o a aquellas en que los juicios políticos llevan a considerar la agencia del sujeto siempre en oposición al poder. En la teoría de la formación del sujeto de esta autora, los efectos del poder social aparecen como estructuras dinámicas y productivas que inician al sujeto, sostie-

\footnotetext{
ble.

${ }^{4}$ La autora utiliza el término ineluctabilidad; su sinónimo parece más comprensi-

5 Georg W. F. Hegel (1806), Phenomenology of Spirit, Oxford, Oxford University Press, 1977.
} 
nen su agencia, $\mathrm{y}$ pueden oponerse y transformar las condiciones que las generan.

\section{Sobre la formación del sujeto}

El punto de partida de esta teoría es la noción de poder de Foucault, en la que el sujeto surge como un efecto ambivalente del poder: lo subordina y lo produce. En la teoría de Butler, el sujeto no sólo depende del poder para su existencia, sino que éste constituye la condición misma de su reflexividad -entendida como formación y funcionamiento de la conciencia-. Butler justifica ampliamente el carácter tropológico de su análisis, es decir, se apoya en una figura del lenguaje o tropos de producción que "vuelve sobre sí misma". Una forma de denominar tal figura es la conciencia. En el proceso de formación de la conciencia, el sujeto se inaugura mediante una sumisión primaria al poder, que consiste en una dependencia sobre un discurso que inicia y sostiene su agencia.

Para la autora, la formulación foucaultiana adquiere una valencia psicoanalítica en el momento que se considera que ningún sujeto surge sin un apego pasional hacia aquellos de quienes depende. El sujeto se forma en subordinación debido a la dependencia primaria del infante, y esa misma subordinación le proporciona la condición de posibilidad continuada de su existencia. Para que el sujeto surja, este apego tiene que establecerse y ser negado. El sujeto busca desentrañarse, adquirir el sentido del "Yo", por medio de la negación de ese apego; su búsqueda marca la agencia de un deseo que apunta hacia su disolución, y el sujeto se coloca como barrera ante ese deseo. Este sujeto vuelto contra sí mismo aparece como la condición de su persistencia. En este sentido, el sujeto se construye en ambivalencia, pues al oponerse a la subordinación, reitera su sujeción, pero al mismo tiempo el sujeto se apropia de la sujeción; esta apropiación constituye el instrumento de su devenir y de su agencia.

En esta formulación Butler reconoce una paradoja temporal que también se asocia con el sitio de donde emerge el sujeto. Ella asegura que ningún individuo deviene en sujeto sin haber sido sometido (experimentado subjetivación) en sentido foucaultiano, es decir, sin haber sido producido discursivamente. De tal manera que el sujeto surge como una consecuencia del lenguaje, y por ende debe ser designado como una categoría lingüística, 
una posición, una estructura en formación, que es inaugurada por medio de una inversión en el horizonte del poder. Este horizonte aparece bajo dos modalidades temporales: el poder que es siempre anterior al sujeto, que está fuera y opera desde el principio; y el poder que es el efecto deseado del sujeto. No existe transición alguna entre ambas modalidades, lo que ocurre es un encubrimiento en que el poder aparece como si perteneciera exclusivamente al sujeto; ello implica que las condiciones de poder asumen una forma presente y futura, en tanto la apariencia del poder cambia de la condición para la formación del sujeto, a los efectos deseados del sujeto. El poder asume este carácter presente gracias a la inversión de su dirección, que rompe con el poder anterior y se disimula como una agencia autoinaugurante. Pero para que las condiciones de poder persistan, tienen que ser reiteradas, y el sujeto es el sitio de esa reiteración. La reiteración del poder vuelve temporales las condiciones de subordinación, y muestra que éstas son estructuras temporalizadas, activas y productivas. El poder es rearticulado por el sujeto, hecho nuevamente, una y otra vez.

$\mathrm{Al}$ igual que Foucault, Butler vincula la dimensión formativa y productiva (es decir, proclama al sujeto y lo produce por medio de la subjetivación) del poder con los regímenes disciplinarios y reglamentarios. Sostiene que si la formación del sujeto se lleva a cabo de acuerdo con los requisitos del poder reglamentario, específicamente la incorporación de normas, el proceso por el cual éstas son incorporadas crea la distinción entre la vida interior y la vida exterior, cuya frontera es instalada mediante la regulación misma del sujeto, pues el poder social crea modalidades de reflexividad, al mismo tiempo que limita las formas de sociabilidad. No puede ser de otra manera, porque la producción del sujeto y la operación psíquica de la norma derivan de las condiciones de poder que le preceden: son la consecuencia de un apego pasional a la sujeción, de una subordinación primaria a un discurso, que lo convierten en un ser vulnerable por su deseo de continuidad, de existir. La sujeción explota este deseo, donde la existencia siempre es conferida desde algún otro lugar, y marca la vulnerabilidad hacia el Otro para poder existir. Para explicar el proceso de incorporación de la norma, Butler, siguiendo a Freud, distingue dos tipos de prohibiciones: la represión y la exclusión.

La elaboración de la esfera interna del sujeto puede ser entendida como el efecto de una prohibición internalizada, represión, que hace volver "la pulsión” (anhelo o deseo) sobre sí 
misma. Este retroceso se convierte en la condición de la formación del sujeto y produce el hábito psíquico de autocondena, que se consolida con el tiempo como conciencia, siendo ésta el medio por el cual un sujeto deviene en objeto para sí mismo, reflejándose, estableciéndose como reflejado y reflexivo. La "vuelta" o "retroceso" del deseo, que culmina en reflexividad, produce otro orden de deseo: el deseo por ese circuito, deseo por la reflexividad, y en última instancia, por la sujeción. Pero Butler distingue otro tipo de prohibición que marca los límites de reflexión, es la exclusión. A diferencia de la represión, en la que el deseo pudo haber existido separado de su prohibición, la exclusión presupone que el deseo es rigurosamente eliminado, constituyendo al sujeto mediante un tipo de pérdida anticipada: una melancolía constitutiva.

La melancolía implica la doble negación de un apego, pues al mismo tiempo que es apartada, se la integra en la formación de la conciencia. Es una esfera de apego que no se produce explícitamente como un objeto de discurso, pero estructura las formas que cualquier apego puede asumir, porque no solamente sitúa objetos, sino que los regula y normaliza por medio de esa colocación. Esto explica que en el psicoanálisis "el carácter del ego" aparezca como la sedimentación de objetos amados y perdidos, el remanente de una aflicción irresuelta. En principio, parecería que la aflicción se resuelve mediante una ruptura con el apego y la construcción de uno nuevo. Empero, no hay una ruptura final, sino más bien una incorporación de ese apego como identificación, es decir, el objeto continúa recorriendo el ego como una de las identificaciones que lo constituyen. En ese sentido, la identificación melancólica conserva al objeto como parte del ego, transfiriendo su condición de externo a interno; en la internalización, la pérdida es parte del mecanismo de su rechazo. De acuerdo con esta propuesta, los funcionamientos del poder social pueden ser leídos en la delimitación del campo de los objetos que son excluidos, pues en tanto que exclusión, la sanción social funciona para producir ciertos tipos de objetos y para excluir otros del campo de la producción social.

Más aún, la incorporación melancólica aparece en la utilización de las figuras del lenguaje empleadas para explicar la psique. Butler sostiene que en la explicación de la formación de la psique surge la figura de "la vuelta" como un tropo (figura del lenguaje) constitutivo del discurso psíquico, en el que la articulación del espacio psíquico, figurado como interno, depende de la 
“vuelta” melancólica: "La vuelta del objeto al ego que produce el ego y sustituye al objeto" (Freud). Esa vuelta del objeto al ego es el movimiento que hace posible su distinción, es decir que la vuelta produce la división entre el ego y el objeto, los mundos interno y externo. Por tanto, la melancolía inicia una frontera variable entre lo psíquico y lo social, que distribuye y regula la esfera psíquica con relación a las normas prevalecientes de regulación social.

\section{Entre Foucault y Althusser}

En su explicación sobre la manera en que el poder reglamentario produce y mantiene a los sujetos en subordinación, y explota su demanda por continuidad, visibilidad y lugar, destaca la lectura que Butler efectúa de Foucault y de Althusser. Con ambos autores subraya la importancia de la dimensión psíquica, así como los efectos formativos de la prohibición en la producción y regulación del sujeto, y reafirma la utilidad de la incorporación melancólica. Por una parte, muestra que el sujeto en el pensamiento foucaultiano no es lo mismo que el cuerpo del que surge, y hace énfasis en su carácter incompleto. El sujeto permanece como tal sólo por medio de la reiteración de sí mismo; una repetición (iterabilidad) en la que el sujeto busca coherencia en categorías sociales que son rearticuladas y resignificadas por él mismo. De acuerdo con su exposición, esta iterabilidad abre posibilidades para oponerse y transformar los términos sociales que lo generan. Por otro lado, con la teoría de la interpelación ejemplifica los efectos psíquicos de la norma. A continuación se exponen los puntos más importantes en ambos casos.

Es necesario recordar aquí que, de acuerdo con Butler, la noción de subjetivación en el pensamiento de Foucault se refiere a la producción discursiva de identidades, y que en ese sentido el término conlleva una paradoja, pues implica el devenir del sujeto y el proceso de sujeción. Butler explica que para Foucault, el proceso de subjetivación se lleva a cabo básicamente por medio del cuerpo, pero sostiene que la subjetivación no puede explicarse sin dar cuenta de los efectos formativos o generativos de la restricción o prohibición. De hecho, indica que la formación del sujeto no puede ser pensada sin recurrir a un juego habilitante de restricciones que lo fundan. Siguiendo esta línea, Butler discute los alcances de la conocida frase foucaultiana "el alma, la prisión del cuerpo". Desde su punto de vista, la resistencia que Foucault 
atribuye a los discursos normalizadores debe atribuirse a la psique, que incluye el inconsciente. Según Butler, la explicación foucaultiana de que los discursos encarcelan al cuerpo en el alma, presupone reducir la noción de la psique a las operaciones de un marco externo e ideal normalizador; como si recibiera unilateralmente el efecto de lo simbólico, en el sentido lacaniano. No obstante, Butler anota que Foucault, por una parte, en Historia de la Sexualidad ${ }^{6}$ sugiere que hay una "interioridad" del cuerpo que existe antes de la invasión del poder. Pero por otra parte, en Vigilar y Castigar 7 parece que la "interioridad", el alma, es tomada como un instrumento del poder, con la cual el cuerpo es formado y cultivado. En el segundo caso, Butler anota que Foucault aborda la formación del sujeto efectuada, en alguna medida, por medio de la subordinación del cuerpo y aun de su destrucción; el sujeto toma el lugar del cuerpo y actúa como el alma que enmarca y forma al cuerpo en cautiverio. Según la autora, el alma exterior puede ser entendida como la sublimación del cuerpo, y el cuerpo debe ser entendido como aquello que no sólo constituye al sujeto en su estado disociado y sublimado, sino que excede o resiste cualquier esfuerzo de sublimación. En cuanto a la resistencia, Butler recuerda que ésta aparece en el pensamiento de Foucault, por una parte, en el curso de la subjetivación que excede los objetivos normalizadores, y por otra, en la convergencia con otros regímenes discursivos. Sin embargo, allí la subjetivación alcanza sus límites y su poder habilitante; esto es así porque el sujeto no está consolidado, siempre se encuentra en proceso de producción, es producido repetidamente. En esta repetición del sujeto, los términos que lo forman y lo enmarcan movilizan un discurso inverso en contra del régimen de normalización que los genera, y corren el riesgo de ser reformulados. Butler acota, empero, que los discursos no sólo constituyen el dominio de lo "decible”, sino que están ligados por medio de la producción a una exterioridad constitutiva: lo indecible, lo insignificable.

Para explicar cómo se rompe la producción disciplinaria del sujeto, Butler recurre a Althusser y sostiene con él que el esfuerzo representativo (performative) de nombrar, sólo puede intentar conferir existencia a su destinatario, pues siempre existe la posibilidad de un desconocimiento; y subraya el uso althusse-

${ }^{6}$ Michel Foucault, Historia de la sexualidad, volumen 1: La voluntad de saber, Madrid, Siglo XXI, 1987.

${ }^{7}$ Michel Foucault, Vigilar y castigar: Nacimiento de la prisión, México, Siglo XXI, 1988. 
riano de Lacan, quien se centra en la función de lo imaginario como la posibilidad permanente de desconocimiento, esto es, la inconmensurabilidad entre una demanda simbólica y la inestabilidad de su apropiación. Si el nombre interpelado busca lograr la identidad a la que se refiere, empieza como un proceso representativo (performative) que, no obstante, es desviado en el imaginario. En esta línea, la autora continúa interrogando a Foucault, y advierte que aunque en Vigilar y Castigar Foucault presume la eficacia de la demanda simbólica, de su capacidad representativa (performative) para construir al sujeto que nombra, en la Historia de la Sexualidad existen tanto un rechazo a "un solo lugar de sublevación”, así como una afirmación de las múltiples posibilidades de resistencia habilitadas por el poder mismo. Butler manifiesta que a diferencia de Lacan, quien restringe la noción del poder social al dominio simbólico y delega la resistencia al imaginario, Foucault reelabora lo simbólico como relaciones de poder y entiende la resistencia como uno de sus efectos, pues la concepción de Foucault se desplaza desde un discurso jurídico hacia otro sobre el poder, que es el campo de las relaciones productivas, reglamentarias y contestatarias.

En este sentido, para Foucault lo simbólico produce la posibilidad de sus propias subversiones como efectos no anticipados de las interpelaciones simbólicas. Lo simbólico no sólo consiste en la reiterada elaboración de normas o demandas interpelativas, pues el poder en el pensamiento de Foucault es formativo o productivo, maleable, múltiple, expansivo y conflictivo. Así, el discurso no constituye a un sujeto unilateralmente, o más bien sí lo hace; simultáneamente, también constituye la condición para su deconstitución. Aquello a lo que se confiere existencia por medio de la demanda interpelativa, es mucho más que un "sujeto", porque el "sujeto" no está fijo en un lugar, permanece como tal a través de la reiteración o rearticulación de sí mismo como sujeto, y esta dependencia en la repetición constituye su carácter siempre incompleto. Esta iterabilidad se convierte en el no-lugar de la subversión, la posibilidad de una repersonificación de la norma subjetivante que puede redirigir su normatividad. Para Foucault, entonces, el aparato disciplinario produce sujetos; pero como una consecuencia de esa producción, trae al discurso las condiciones para subvertirlo.

Con Althusser, Butler se centra en la teoría de la interpelación que aparece en el ensayo "Ideología y Aparatos Ideológicos del Estado”, y advierte explícitamente que esta teoría es releída y 
discutida en conjunto con las metáforas y los ejemplos que usa el autor. ${ }^{8}$ Desde su punto de vista, la teoría de la interpelación es una forma de explicar al sujeto como consecuencia del lenguaje y siempre dentro de sus términos. Sostiene que en el ejemplo de interpelación de Althusser, el acto de "voltear" del sujeto ante un llamado no parece estar determinado unilateralmente, o exhaustivamente, ni por la ley ni por el destinatario. El "voltear" puede ser entendido como un movimiento anticipado hacia la identidad por medio de la autoadscripción de la culpa, como una "vuelta en contra de sí mismo" que constituye el movimiento de la conciencia. La aceptación de los términos por los que uno es llamado se debe a que, anterior a cualquier posibilidad de entendimiento crítico, preexiste una apertura, o vulnerabilidad a la ley; una complicidad pasional sin la cual ningún sujeto puede existir. Según Butler la teoría de la interpelación puede situar la vulnerabilidad de la subjetivación en esa vuelta hacia y en contra de la ley, porque presupone una doctrina no elaborada sobre la conciencia, una "vuelta sobre sí mismo", que trae consigo la disposición de aceptar la culpa para adquirir una porción de identidad. La posibilidad de formación del sujeto depende de una búsqueda apasionada por el reconocimiento, que es inseparable de la culpa. Debe entenderse, entonces, que la autorrestricción es anterior al sujeto y se encuentra vinculada con la posibilidad del habla, pues la interpelación social está estructurada por el poder de nombrar, y el nombrar hace que los sujetos existan. El nombre aparece como la condición anterior y esencial a la formación del sujeto y muestra que hay una cierta disposición a ser subyugado por la interpelación, una disposición que sugiere que ya se encuentra implicado en los términos de la autoridad, a los que subsecuentemente cede, o que ha cedido antes de voltear y que la vuelta es un signo de una sumisión inevitable. En esta sumisión el sujeto es establecido como un sujeto colocado en el lenguaje.

Butler explica que el surgimiento de la conciencia (conocimiento), según Althusser, se relaciona con el proceso de adquisición de habilidades que tienen que ser aprendidas para luego ser reproducidas. La autora afirma que en el pensamiento althusseriano las habilidades lingüísticas son fundamentales para la formación del sujeto, y constituyen las reglas y actividades observadas. Las habilidades en general, pero las lingüísticas en particular,

${ }^{8}$ Louis Althusser, "Ideología y Aparatos Ideológicos del Estado", en Louis Althusser, La filosofía como arma de la revolución, México, Siglo XXI, 1986. 
tienen que ser dominadas y dominables; su dominio aparece como un tipo de sumisión. Entre más sea dominada una práctica, mayor será la sumisión. De tal modo que sumisión y dominio se llevan a cabo simultáneamente. Por lo tanto, aquello anterior al sujeto que puede explicar su formación, es la reproducción de las habilidades sociales, la reproducción de la sujeción. Aquí la reproducción central es la del sujeto, y se lleva a cabo con relación al lenguaje y a la formación de la conciencia. Realizar tareas "conscientemente" significa realizarlas una y otra vez para reproducir esas habilidades, y al reproducirlas, adquirir dominio.

Desde esa perspectiva, la autora insiste en que el dominio de un juego de habilidades debe ser interpretado como una absolución de uno mismo; este dominio lo defiende a uno contra una acusación; es la declaración de inocencia del acusado. Asegura que desde el pensamiento de Althusser, convertirse en un "sujeto" implica haber sido presumido culpable, entonces tratado y declarado inocente. Debido a que esta declaración es incesantemente producida, convertirse en un "sujeto" significa estar en el proceso de absolverse uno mismo de la acusación de culpa. Pero como esta culpa condiciona al sujeto, constituye la prehistoria de la sujeción a la ley por la cual el sujeto es producido. La actuación (performance) del sujeto no está simplemente en concordancia con la reproducción de las habilidades sociales, porque no existe sujeto anterior a su realización; realizar tareas laboriosamente introduce al sujeto a su condición como ser social. Hay culpa y entonces se realiza una práctica repetitiva por medio de la cual se adquieren las habilidades, y sólo entonces se adquiere el lugar gramatical dentro de lo social como sujeto. Dominar un juego de habilidades significa reproducirlas en y como una actividad propia. Esto implica incluir reglas en el curso de acción, y reproducir esas reglas en rituales personificados de acción.

La dimensión psíquica es inseparable de la repetición ritual de los actos, pues la noción misma de ritual implica traducir creencia y práctica como inseparables. Pero inherente a cualquier actuación existe una compulsión de "absolverse uno mismo", y entonces, anterior a cualquier actuación, preexiste una ansiedad y un conocimiento que deviene articulado y animado sólo sobre la ocasión de la reprimenda.

Con esta explicación Butler reitera la importancia que Althusser atribuye a la dimensión psíquica, y afirma que la contribución distintiva de este autor es la de socavar el dualismo ontológico presupuesto por la distinción marxista convencional, entre 
la base material y la superestructura ideológica. La constitución del sujeto es material en la medida en que se lleva a cabo mediante rituales, y éstos materializan "las ideas del sujeto". Lo que se denomina subjetividad, entendida como la experiencia vivida e imaginaria del sujeto, es en sí misma derivada de los rituales materiales por los que el sujeto es constituido.

No obstante, Butler asevera que Althusser fracasa al no poder dar cuenta de un "remanente de interioridad" que no se toca en la interpelación: el amor. El amor está más allá de la interpelación porque es generado por una ley inmaterial (lo simbólico) sobre y por encima de las leyes rituales que gobiernan las diferencias prácticas de amor. El Otro que surge aquí es de orden simbólico, y como tal se pierde, se introyecta, se convierte en la condición inmaterial del sujeto, inaugura la repetición específica de lo simbólico, la fantasía de un retroceso que nunca puede ser completado. A medida que la introyección primaria es un acto de amor, éste es reiterado, y por ende es ritual. Althusser supone un apego pasional a la ley, pero el amor no está más allá de la interpelación. La interpelación no tiene éxito, no por ser una forma estructural de prohibición, sino por su inhabilidad para determinar el campo constitutivo de lo humano. Si la conciencia es una forma que toma el apego pasional a la existencia, entonces la falla de la interpelación debe ser encontrada en el apego pasional que le permite funcionar: en la identificación melancólica.

\section{Formación melancólica del género}

Finalmente, Butler lleva sus propuestas teóricas a un análisis sobre la formación del género, con el que reafirma sus puntos de vista acerca de la incorporación melancólica de la norma. Sostiene que en la cultura occidental existe una matriz heterosexual que penetra en la construcción del género, que incluso se encuentra en la explicación de Freud sobre el complejo de Edipo. Esta matriz es una construcción exagerada y rígida de la relación entre género y sexualidad en la cual las posiciones de "masculino" y "femenino" son establecidas, en parte, por medio de prohibiciones que demandan la pérdida de ciertos apegos sexuales, y que exigen además que esas pérdidas no sean declaradas ni sufridas. Esto implica que la heterosexualidad se adquiere, en cierto grado, mediante prohibiciones que toman como uno de sus objetos el apego homosexual, forzando con ello la pérdida de esos 
apegos. Siguiendo la línea psicoanalítica, Butler explica que en la formación del ego esta pérdida es conservada como una identificación rechazada, en la que los objetos homosexuales quedan excluidos desde el principio. En esta identificación no hay reconocimiento o discurso con el cual la pérdida pueda ser nombrada o sufrida. La heterosexualidad se naturaliza a sí misma subrayando la alteridad de la homosexualidad, y por tanto, la identidad heterosexual se consigue por medio de una incorporación melancólica del amor que rechaza. Es decir, se trata de una identidad basada en el rechazo a declarar un apego, y por ende, el rechazo a sufrir.

Más aún: cuando la prohibición contra la homosexualidad es culturalmente penetrante, la pérdida es precipitada mediante una prohibición que se repite, y ritualiza en toda la cultura: una cultura de la melancolía de género en la que el logro heterosexual es reforzado con el rechazo. Butler establece que en esta concepción el género se entiende como aquello que permanece inarticulado en la sexualidad, pues sólo de esta manera es posible entender cómo el deseo homosexual deviene una fuente de culpa. La melancolía está marcada por la experiencia de la autocondena, en la que la culpa surge como la vuelta del apego homosexual al ego. Si la pérdida se convierte en una escena renovada de conflicto, y si la agresión que sigue a la aflicción no puede ser articulada o externada, entonces rebota en el ego mismo, en la forma de superego. En este sentido, la melancolía aparece como el rechazo de la pena y como la incorporación de una pérdida. Así, la prohibición de la homosexualidad anticipa el proceso de la pena y estimula una identificación melancólica que vuelve el deseo homosexual sobre sí mismo; es la acción de la autocondena y la culpa. La homosexualidad no es abolida, sino conservada en su prohibición.

Por lo tanto, según esta autora, es posible leer en la melancolía el funcionamiento del género, debido a que en ésta el mundo aparece como contingentemente organizado mediante ciertos tipos de exclusión. Asegura que cualquier forma rígida de género, sea heterosexual u homosexual, origina formas de melancolía. Ello ocurre porque el género es representativo (performati$v e$ ), es decir, la actuación de género produce retrospectivamente la ilusión de que hay un núcleo interior al género (el efecto de una esencia o atribución verdadera o permanente); pero el género se produce como una repetición ritualizada de convenciones socialmente obligadas, y puede ser entendido como "la actua- 
ción” de una aflicción no resuelta. Butler apoya su argumento al explicar que en el travestismo, la constitución "normal” del género representado está compuesta por un juego de apegos rechazados; de identificaciones que constituyen el dominio de lo "no representable".

\section{Consideraciones finales}

El interminable "volver sobre sí mismo" y la incorporación melancólica de la norma en la teoría de Butler sobre la formación del sujeto, también aparece como parte constitutiva de su explicación; constituye un esfuerzo de "re" presentar, a partir de figuras del lenguaje, la diferenciación de los espacios "interno" y "externo". Su trabajo es un ejemplo claro de ese "volver sobre sí mismo" que imprime un carácter dinámico a las categorías sociales. Es necesario destacar que la sumisión del sujeto a un discurso que tiene el poder de formarlo y regularlo por medio de la imposición de categorías del lenguaje, no presupone una determinación lingüística anterior al sujeto; recuérdese que el sujeto es una estructura en formación. En este sentido, quizás habría que insistir en la noción de iterabilidad, tanto de las categorías como del sujeto.

En la teoría de la formación del sujeto hay individualidad, pero en cada caso no es del todo particular; las categorías del lenguaje con las que el sujeto se coloca en el mundo social están dadas de antemano, pero son reformuladas y el sujeto reformula su existencia por medio de las mismas. Además, la alteridad que produce al ego mediante la incorporación melancólica de la norma, y que aparece en los actos de autocensura de la conciencia, no permanece estable a través del tiempo. El otro, incorporado por medio de la prohibición, incluye ideales y conceptos que forman parte de la reflexividad del sujeto.

En este sentido, Butler deja una puerta abierta para encontrar otras identificaciones melancólicas en la constitución de la identidad, que no se restringen a la construcción del género, como por ejemplo la identidad nacional, o bien, siguiendo la línea de la autora respecto a las identificaciones melancólicas de género, aquellas asociadas con las representaciones de hogar y de trabajo. Tanto el hogar como el trabajo se encuentran objetivados en el lenguaje, y el hogar encuentra una posible referencia empírica en "la casa”. Además, en el hogar y en el trabajo se reproducen las habi- 
lidades y, por ende, la reflexividad de los sujetos; y el mundo aparece, también, como organizado entre ambas esferas.

¿Qué formas de identificación melancólica yacen bajo la construcción de ambas? ¿Cómo reproducen y representan los sujetos esta dualidad? ¿Qué identificaciones melancólicas les son subyacentes? ¿Es posible identificar señales de cambio a partir de la representatividad (performativity) de los sujetos?

Considero que Butler reintroduce la importancia de la descripción hermenéutica, y abre las puertas a un acercamiento metodológico que incluye la dimensión psíquica, por medio del funcionamiento psíquico de la norma, como una forma de dilucidar los funcionamientos del poder social. 
